\title{
COSPLAYERS COMO FENÔMENO PSICOSSOCIAL: DO REFLEXO DA CULTURA DE MASSA AO DESEJO DE SER HERÓI
}

\author{
COSPLAYERS AS A PSYCHOSOCIAL PHENOMENON: FROM A \\ REFLECTION OF MASS CULTURE TO THE DESIRE TO BE A HERO
}

Leconte de Lisle Coelho Junior*

Sara Santos Silva**

\begin{abstract}
Coelho LdLJr, Silva SS. Cosplayers como fenômeno psicossocial: do reflexo da cultura de massa ao desejo de ser herói. Rev Bras Crescimento Desenvolv Hum 2007;17(1):64-75.

Resumo: Este estudo visou entender o que leva as pessoas a produzirem cosplays, ou seja, o que origina o comportamento de travestir-se como os heróis de desenhos animados e mangás, mais notadamente os animés (desenhos animados japoneses) e quais as consequiências de tal motivação. A coleta de dados se deu entre o mês de outubro de 2003 e outubro de 2004 nas cidades de São Paulo (SP) e Aracaju (SE) sendo que a amostra contou com 26 participantes cuja média de idade era de 17,5 anos $(\mathrm{DP}=3,42)$. Utilizou-se a análise qualitativa no formato de entrevistas para melhor detectar a ocorrência do fenômeno e sua explicação. Os resultados mostraram que os jovens seguem essa preferência porque isso os afasta do seu contexto cotidiano, ou seja, o fato de adotarem o perfil do personagem e de, principalmente, vestirem-se como eles encarnando-os, serviria como uma forma de busca por um bem-estar que ajudaria a manter o equilíbrio no dia a dia.
\end{abstract}

Palavras-chave: Cosplay. Animés. Mangás. Otakus. Cultura de massa. Juventude. Cultura japonesa.

\section{INTRODUÇÃO}

Redes de comunicação que se estabelecem entre os membros ajudam, e mesmo permitem, a sua manutenção, assim como possibilitam o que se denomina atualmente cultura de massa. Para Campos e Jobim e Souza1, "as novas tecnologias, o consumo e a influência da mídia marcam, modelam e constroem as subjetividades contemporâneas" (p.20).

Neste sentido, cabe à psicologia, entre outras tarefas, tentar entender o pensamento e o comportamento social dos grupos e o que leva coletividades de pessoas a tomar decisões que compõem seu repertório condutual, além das interações com os meios de comunicação ${ }^{1-5}$.
A consolidação do modo capitalista de produção vai influir diretamente na subjetivação humana $^{3}$. Ainda assim, o capitalismo favoreceu o fomento de movimentos marginais, o que vai determinar o surgimento dos direitos humanos e consequentemente o interesse e a busca pelo bemestar social, seja pelo Estado, seja pelos próprios indivíduos constituintes da sociedade.

É neste contexto que se avalia o fenômeno focado nesta pesquisa: a emergência de uma sociedade de entretenimento onde os cosplayers seriam um dos inúmeros acontecimentos deste moderno formato societal.

A pesquisa leva em consideração a modernidade como fenômeno social e de subjetivação ao enfocar o fenômeno psicossocial dos cosplayers:

\footnotetext{
Doutorando no Programa de Pós-Graduação em Psicologia da Universidade Federal do Espírito Santo (UFES). Professor substituto nesta mesma instituição. Endereço: Rua Carlos Delgado Guerra Pinto, n²65, ap. 211. Cep.:29090-040.Email: lecontey@yahoo.com.br

** Graduada em Psicologia pela Faculdade Pio Décimo de Aracaju (Se).
} 
termo derivado das palavras inglesas: $\cos =$ costume, traje, fantasia e play = brincar, jogar o que pode ser entendido como 'brincar de costumes', 'brincar de teatro' ou simplesmente 'roupa de jogador'.

Entre inúmeras definições do que sejam os cosplayers, pode-se citar:

"Fazer um cosplaynãoé somente vestir uma roupa, mas encarnar um personagem, seu jeito, suas poses, seu modo de falar, de se portar. Cosplay é se fantasiar do seu personagem favorito, seja ele de um animê videogame ou comic". 4

Ou como afirma Luyten ${ }^{5}$ :

“(...) mangás e animês são encenados em peças de teatro e telenovelas, viram tema de músicas, alimentam leilões de edições raras $e$ encontros com desfiles de cosplay, quando os fãs encarnam os heróis de suas aventuras prediletas usando os trajes dos personagens." (p.51).

Os cosplayers, ou seja, aqueles que se vestem como personagens dessa forma de mídia, de uma maneira mais ampla, podem também ser denominados de 'otakus', como veremos a seguir. São pessoas, geralmente jovens adolescentes, que copiam as roupas e trejeitos de seus heróis favoritos (em sua grande parte, personagens de desenhos animados japoneses) e que sentem satisfação com tal ato. Para sua reunião, congregam-se em eventos públicos onde possam ser apreciados e comparados aos ditos personagens animados que são exibidos concomitantemente em salas de vídeo.

O referencial da psicologia social societal ${ }^{8-}$ ${ }^{10}$ entende o mundo como algo em permanente construção. Segundo Farr' ${ }^{9}$ a vertente societal da Psicologia Social decorreu da 'crise da psicologia' ocorrida durante a década de 70 do século anterior, quando predominava a perspectiva experimental e individualista norte-americana, permeada por uma prática contraditória e obsoleta. Com o desenvolvimento da Teoria das Representações Sociais de Serge Moscovici ${ }^{7}$ e também da Teoria da Identidade Social de Henry Tajfel ${ }^{8}$, a psicologia societal começa a ser desenvolvida baseando-se no estudo dos processos representacionais e identitários dos grupos e de seus membros.
Para Farr ${ }^{9}$ e Moscovici ${ }^{7}$, essa nova psicologia social estaria se orientando para um diálogo com a sociologia, perdido anteriormente por causa de polêmicas científicas, ocorrendo então, desta forma, um distanciamento da antiga prática adotada pelos norte-americanos. Esta posição reiterou a necessidade de se explorar os eventos ocorridos nos ambientes sociais de cada pesquisador, promovendo uma maior liberdade de ação. Para Moscovici ${ }^{7}$ as demandas determinam as complexas relações impetradas pelos humanos no campo social por eles construídos.

Desta perspectiva, o estudo teve como objetivo captar as representações identitárias formalizadas pelos cosplayers acerca do que eles construíram em suas interações com a mídia televisiva e impressa. Seus objetivos foram verificar a existência de: 1. uma ligação da identidade dos cosplayers e produções de mídia; e, 2. um processo de infantilização marcando as pessoas desta faixa etária.

Como tais personagens estão contidos em formas muito específicas de meios de comunicação, principalmente animações artísticas japonesas (animés), e como muitos destes provêm de revistas em quadrinhos também nipônicas (os mangás), exporemos algumas explanações acerca destas fontes de arte.

\section{A psicologia do mangá e dos animés}

Segundo Coelho Junior ${ }^{8}$ e Luyten ${ }^{9}$ com a chegada do Budismo ao arquipélago nipônico houve uma total dinamização social, não somente pelo desenvolvimento da escrita, mas também pelos costumes adquiridos do continente via China. Um destes costumes foi à construção de templos como, por exemplo, os de Toshodaiji e Horyuji na cidade de Nara.

A importância destes templos não só denota a questão histórico-religiosa, mas também ali foram encontrados, em 1935, desenhos escondidos que retratavam caricaturas do cotidiano japonês, bem como a história de vida de alguns personagens da política e do mundo religioso locais.

Esses desenhos foram chamados de $\hat{e}$ kimonos e são a origem das histórias em qua- 
drinhos japonesas que especialmente floresceram nos séculos XI d.c e XII d.c. Nesta época estas estórias eram desenhadas em extensos rolos de papel e à medida que iam sendo contados os mesmos eram desenrolados acompanhando o ritmo da verbalização ${ }^{11,12}$.

Foi no Período Edo (1600-1868), com o início da estabilização política e o fim de uma série de guerras civis, que surgiu o predecessor direto dos atuais mangás, o artista chamado Katsushika Hokusai (1760-1849) que compilou estórias com uma série de imagens no centro e vários diálogos em volta.

Havia, naquela época, diferentes tipos de mangás para diferentes classes de pessoas ${ }^{10,11}$. A segunda metade do século XIX foi importante, pois o modelo de arte gráfica Ocidental aderiu ao estilo dos mangás, alterando sutilmente seu formato. Com o início da vinda de colonos japoneses ao Brasil, logo este tipo de produção passou a ser comercializado. Na década de 80 surgiram os primeiros mangás no mercado de literatura brasileiro.

Existe um conjunto de aspectos técnicos inerentes às artes gráficas e eletrônicas que permitem que o consumidor se apegue e se identifique com estas produções que, por sua vez, não pertencem à sua cultura. Esta 'universalização' é própria da linguagem de cultura de massa, embora muitos temas sejam comuns somente à nacionalidade japonesa. Moliné ${ }^{10}$ entende que a variedade dos temas, a exposição da psicologia das personagens, o ritmo narrativo, layout das produções, recursos secundários específicos são o diferencial para que haja a disseminação dessa arte Oriental. Já Parente ${ }^{12}$ inclui:

- Figuras estilizadas: a grande maioria das personagens possui a mesma aparência, isto é, olhos grandes e redondos, queixo e nariz pequenos;

- Narrativa cinematográfica: segue a necessidade artística do cinema em demarcar detalhadamente quadro a quadro mudanças de expressão das personagens e novos ambientes;

- Inconstância temporal: diferente do padrão de comics, na arte do mangá/animé, os personagens seguem a seqüência temporal comum às pessoas da vida real, isto é, nascem, possuem infância, adolescência e morrem, o que finaliza completamente uma série de mangá/animê; e,

- Preocupação com a temática sexual: necessidade decorrente de uma cultura muito rígida, o que não significa que não haja material específico onde apareçam atos sexuais.

Concernente ao aspecto psicológico das personagens, é interessante notar que estes não possuem um mesmo perfil genérico como ocorre nos comics Ocidentais, ou seja, o herói não é imbatível. Ele possui uma vida particular, que muitas vezes se assemelha à de um indivíduo comum, que possui dificuldades comuns no seu dia-a-dia. Aliás, característica natural aos protagonistas destas estórias é que muitos não possuem "superpoderes", caracterizando indivíduos triviais em muitas destas personagens.

Talvez isto permita que muitas pessoas identifiquem-se ao notarem suas vidas espelhadas em muitas destas personagens. Daí a enorme variedade de tipos de estórias. A psicologia, o aspecto subjetivo do herói, pode ser muitas vezes tão somente um reflexo do que seja o autor, ou, simplesmente, uma dupla-imagem do que seja o público ao qual ele se destina.

A psicologia da personagem de animé e mangá, vista deste ponto, determina uma variedade ímpar de ações estilizadas, o que serve como delimitador desta diversidade. Muitas vezes, entender que as personagens atuam na estória de uma maneira que não está distante de sua própria realidade faz com que os consumidores dessa mídia criem uma espécie de vínculo. Outro item é o conjunto de emoções existentes entre os personagens, o que os torna muito humanizados.

Apesar disto, Andrade ${ }^{13}$ caracteriza de forma geral os desenhos animados em três grupos: desenhos educativos, desenhos de entretenimento e desenhos violentos. Esta autora classifica os animês na última categoria, ou seja, a dos desenhos animados violentos e agressivos. Daí então, de certa forma estes conteúdos serem vistos como 'anormais' e indesejáveis, pois não se pode esquecer que essas ficções que são muitas vezes baseadas em eventos históricos verídicos são partes de uma cultura que não é Ocidental, e que por isto pode haver uma percepção limitada do que gera tal conjunto de signos. 
Isto converge com o que colocam Bosi ${ }^{14} \mathrm{e}$ Moscovici ${ }^{7}$ em suas pesquisas sobre a flexibilidade da instância imaginária humana. No primeiro caso, ao destacar a produção de massa enquanto aquela que destrói, subverte e substitui a cultura popular, e no segundo caso, em como os contatos sociais permitem que as estratégias dos grupos sociais consigam uma dinamicidade da vida real, não importando de certa forma o destino final das produções psicossociais.

\section{A psicologia dos cosplayers: Os otakus}

Como conseqüência desta movimentação na subjetividade da vida social, com a criação quase infinita de construções e reconstruções de conjunturas que frutificam em novas nuances de habitus é que se verifica a inovadora arte otaku. Segundo $\mathrm{Barral}^{2}$ o que é designado como otaku nada mais é do que fazer parte da nova sociedade humana que vai se apoiando na tecnologia do virtual (homo virtuens), sendo assim:

“Em japonês, o termo otaku possui dois significados primordiais, que já existiam na língua antes do aparecimento do fenômeno em si. O primeiro corresponde à leitura de um dos caracteres japoneses utilizados para designar a habitação, o lugar onde se vive. O segundo significado da palavra é uma extensão do primeiro sentido: é um tratamento impessoal de distanciamento que os japoneses utilizam quando precisam dirigir-se a alguém sem, contudo, desejar aprofundar a relação travada (...) os otakus têm aversão a aprofundar as relações pessoais, e preferem ficar fechados em casa (...)” (p. 25).

O fenômeno psicossocial dos otakus no Japão é condizente com a rebeldia, em geral da juventude, com o que se tem de mais tradicional na cultura desse povo que é o sentido de grupo. Pela própria constituição histórica da nação japonesa, esse povo necessitou muito cedo do mecanismo de coesão grupal. Assim, puderam reconhecer-se desde há muito tempo como nação independente. Porém proporcionou também a preponderância total do grupo sobre o indivíduo o que, numa sociedade fechada onde não se permite que o 'Outro' (estrangeiro) tenha sequer uma participação social, produz um controle condutual extremamente rígido ${ }^{18}$. Levando-se em conta o que informa $\mathrm{Mancebo}^{2}$, a subjetividade humana tende cada vez mais a uma individualização, e isto vai de encontro ao que preconiza a sociedade nipônica, onde o grupo deve prevalecer sempre.

Em termos culturais, Benedict ${ }^{18}$ afirma que a busca pela autonomia tão natural aos padrões ocidentais, é dificultada aos japoneses, pois o grupo pressiona o indivíduo a constantemente se manter identificado a ele, sendo que se esta identificação é quebrada, surge um profundo sentimento de vergonha, em oposição ao natural sentimento de culpa cristão que permeia a vida em sociedade das coletividades ocidentais. Tal sentimento seria uma barreira para evitar a separação das pessoas de seu grupo de origem, mantendo assim a coesão dos membros. Sendo otaku, o indivíduo se aparta do seu grupo, o que sem dúvida é um choque social. O processo de modernização levou a que o sujeito possua seu bem-estar quando está a sós com sua maquinaria moderna (aparelhos de televisão, microcomputadores, aparelhos de DVD etc.) ao invés de estar compartilhando dos interesses do grupo.

Esse distanciamento pode indicar que o valor das mercadorias substitui o valor do Homem $^{1,3}$, quando o gênero humano se 'coisifica', tornando-se algo sem qualidade, pois que o mais importante é o lucro financeiro. Associado à produção das novidades tecnológicas das quais os otakus se fazem senhores, eles passam por se aterem mais à busca pela diversão por esses aparelhos, desvalorizando a necessidade de convívio com outras pessoas. Isto é o que permite o afastamento do grupo, e a quebra da coesão.

Conforme as autoras acima citadas, esta interferência vem ocorrendo desde a infância. As crianças dariam um destaque a estas tecnologias que muitas vezes pode ser maior do que o contato mais íntimo com os pais, quando estes têm disposição para tal. Neste contexto, vê-se recrudescer modificações já bem perceptíveis sobre o que seria a infância.

Para $\mathrm{Barral}^{2}$, ser otaku significa estar paralisado nesta faixa etária da adolescência, onde 
as responsabilidades sociais são freadas pela barreira do tecnológico. O conhecimento sobre a tecnologia propicia uma comunicação singular entre as pessoas, que proporciona um distanciamento dos outros grupos. Isso produz uma nova fronteira entre indivíduos, uma nova comunicação, derivada da cultura de massas. O aspecto psicológico aí evidente se expressa pela individualização também massificada, onde é comum, em outras palavras, as pessoas terem pouco acesso aos outros, onde cada um se torna estrangeiro dentro do próprio grupo. A relação entre ser otaku e produzir cosplays passa a ficar um pouco mais clara.

De certa forma, cosplayers (otakus) estão tão inteirados quanto às inovações tecnológicas quanto sobre as novidades da arte da animação. Quando se põem a celebrar tamanho conhecimento, criam sua própria 'arte'. Suas reuniões servem também para que o acúmulo de informações seja renovado e, neste momento, os limites, as fronteiras entre as pessoas se tornam mais diminutas e flexíveis. A produção deste fenômeno é algo que já ocorre no Brasil desde os meados da década de 1990, e a cada ano os eventos se tornam mais numerosos (no ano de 2003, São Paulo foi a sede de dois eventos - Animecon e Animefriends - que juntos capitalizaram cerca de 15 mil espectadores e uma cobertura mínima pela mídia impressa e televisiva).

O otaku não somente opera seus conteúdos, mas também faz com que a platéia se envolva, dando os mais diversos significados ao objeto percebido (cosplay). Neste sentido, é importante a exposição do que os próprios cosplayers têm a dizer acerca de sua realidade, para que se possa visualizar o sentido que eles mesmos dão ao que produzem.

\section{MÉTODO}

Segundo Siebra ${ }^{16}$, as pesquisas de cunho qualitativo são aquelas que buscam 'a interpretação subjetiva dos fatos'. Já González Rey ${ }^{17}$ também percebe a necessidade de se manter um padrão de pesquisa de formato qualitativo na ciência psicológica a fim de que se possa entender da melhor forma possível a extensa dimensão da subjetividade humana. Ambas as perspectivas se coadunam com a forma de se proceder em pesquisas da psicologia societal e assimoptouse pela utilização do próprio discurso dos informantes a fim de se compreender o significado de se criarem cosplays.

A amostra foi constituída de 26 (vinte e seis) cosplayers que foram encontrados em 2 (dois) eventos, um realizado na cidade de Aracaju (Se) e outro na cidade de São Paulo (Sp) entre o período de outubro de 2003 e outubro de 2004. Estes eventos reuniram aproximadamente 1.500 pessoas, que se reuniram para discutirem sobre animés e mangás, além de disputar jogos de RPG (Role Playing Game).

A amostra foi escolhida de forma aleatória sendo os participantes abordados durante os eventos onde lhes era explicado a objetivo da pesquisa e se gostariam de participar da mesma. A faixa etária dos participantes esteve entre as idades de 13 e 24 anos sendo a média de idade $17,5$ anos ( $\mathrm{DP}=3,42)$.

Os dados foram coletados a partir de um roteiro de entrevista semi-estruturado cujas questões foram em parte selecionadas no site www.cosplaybr.kit.net.com.br ${ }^{4}$ e em parte de compilação dos autores da pesquisa. Este roteiro contém 12 itens e as respostas foram gravadas (ver anexo). As entrevistas duraram em média 10 minutos.

A análise das respostas foi baseada nas sugestões de Araújo $^{18}$ que demonstra a utilidade da técnica compreensivista para extração dos dados que acabam por facilitar o delineamento dos conteúdos subjetivos que foram verbalizados. Isto se dá ao se separarem as diversas respostas, que vão esclarecer de fato as cognições-afetos que os entrevistados tinham acerca do tema. Uma vez seguindo essas "quebras" sucessivas do discurso dos participantes, o trabalho de categorização fica facilitado. Embora para Niu e Sternberg ${ }^{19}$, a variável socioeconômica seja importante para a investigação acerca da criatividade dos artistas, ela não foi levada em consideração nesta pesquisa pelo próprio formato adotado na mesma e pelas considerações realizadas por estes autores que avisam que tal categoria pode influir na capacidade de desenvolver melhor o papel artístico quando se 
apresenta maior suporte financeiro proveniente da própria sociedade a qual ele faz parte.

Levando-se em conta a Resolução MS $n^{\circ}$ 196/96 do Conselho Federal de Psicologia ${ }^{20}$ que determina as diretrizes e normas de pesquisa envolvendo os seres humanos, os organizadores dos eventos citados receberam um ofício destacando todo o cuidado com o sigilo das informações obtidas (enfatizado durante todas as entrevistas) bem como a garantia da transcrição fiel das respostas.

\section{RESULTADOS E DISCUSSÃO}

Os informantes responderam aos questionamentos do roteiro de entrevista demonstrando o conhecimento que possuíam acerca do assunto. Participaram da pesquisa 26 adolescentes, sendo 10 do sexo masculino e 16 do sexo feminino. Abaixo a Tabela 1 indica a procedência dos sujeitos e seus personagens, como também a origem destes personagens.

Tabela 1 -Amostra / Personagem Exibido

\begin{tabular}{|c|c|}
\hline SUJEITO & PERSONAGEM \\
\hline 1 (Aracaju-SE) & Robert Garcia (King of Fighters) \\
\hline 2 (Aracaju-SE) & Joe Higashi (King of Fighters) \\
\hline 3 (Aracaju-SE) & Miamoto Musashi (Vagabond) \\
\hline 4 (Aracaju-SE) & Sakura Kinomoto (Card Captors Sakura) \\
\hline 5 (Aracaju-SE) & Rambo (Rambo) \\
\hline 6 (Aracaju-SE) & Videl (Dragon Ball Z) \\
\hline 7 (Aracaju-SE) & Miamoto Musashi (Vagabond) \\
\hline 8 (Aracaju-SE) & Benni Maru (King of Fighters) \\
\hline 9 (Aracaju-SE) & Okashira-San (-) \\
\hline 10 (Aracaju-SE) & Kamui Shirou (X-1999) \\
\hline 11 (São Paulo-SP) & Chibi Moon (Sailor Moon) \\
\hline 12 (São Paulo-SP) & Ana Kioyama (Shaman King) \\
\hline 13 (São Paulo-SP) & Seitô-Chan (-) \\
\hline 14 (São Paulo-SP) & Momo Adachi (Peach Girl) \\
\hline 15 (São Paulo-SP) & Miroku (Inu Yasha) \\
\hline 16 (São Paulo-SP) & Seitô-Chan (-) \\
\hline 17 (São Paulo-SP) & Ayame (Inu Yasha) \\
\hline 18 (São Paulo-SP) & Jin (Yu Yu Hakushô) \\
\hline 19 (São Paulo-SP) & Mukuro (Yu Yu Hakushô) \\
\hline 20 (São Paulo-SP) & Malinda (King of Fighters) \\
\hline 21 (São Paulo-SP) & Shocklight (Vampire Hunter’s D) \\
\hline 22 (São Paulo-SP) & Saori Kido/Athena (Cavaleiros doZodíaco) \\
\hline 23 (São Paulo-SP) & Mercenário (Ragnarok on Line) \\
\hline 24 (São Paulo-SP) & Monge (Ragnarok on Line) \\
\hline 25 (São Paulo-SP) & Sacerdotisa (Ragnarok on Line) \\
\hline 26 (São Paulo-SP) & Haki (Blade) \\
\hline
\end{tabular}

Como visto acima, a maioria dos sujeitos era de São Paulo. O maior grupo de pessoas travestidas de um único tipo de mídia foi dos personagens do game nipo-americano King of Fighters $(N=4)$ e do game sul-coreano de internet Ragnarok (jogado on line) $(N=3)$. Duas participantes estavam trajadas como 'Seitô Chan', personagens que são estudantes de ensino médio, muito comum neste tipo de produção e em suma não estavam focalizando especificamente um determinado personagem de mangál animé. Dois (2) informantes utilizaram-se do mesmo figurino relacionado à Miamoto Musashi (do mangá/animé Vagabond). Houve ainda um sujeito (gênero feminino) que se travestiu de 'Okachira-San' (do japonês, patroa; dona de casa), o que também se pode entender como anteriormente, uma personagem comum em mangás e animés.

Do que foi coletado nas entrevistas, seguiuse como sugerido por alguns autores ${ }^{16-18}$ uma caracterização a partir do discurso dos informantes que foi subdividido em categorias conforme os significados explicitados em sua verbalização. Sendo assim, foi inquirido aos informantes se eles possuíam alguma identificação com a personagem que escolheram para realizar o cosplay. A maioria $(60 \%)$ confirmou que havia algum aspecto singular entre o indivíduo e a figura escolhida.

$\mathrm{O}$ discurso das pessoas girou em torno principalmente da aparência, como exposto na entrevista $\mathbf{n}^{\circ} \mathbf{1 4}$ :

"Eu me identifico muito com a minha personagem, tanto psicologicamente como fisicamente (...) muitas meninas, assim se identificam por que a estória de Peach Girl não é tão surrealista... é uma coisa... assim que pode acontecer na vida real".

\section{E ainda na entrevista $\mathbf{n}^{\circ} \mathbf{1 2}$ :}

"É assim... eu gosto muito de animê... sei lá... acho muito parecido comigo esse personagem, gosto muito dele, parece em tudo comigo, cabelo... tamanho, idade... acho assim sabe (...) posso fala que até as coisas que eu gosto... sei lá sabe... ela gosta..." 
Cerca de $40 \%$ não acreditam haver uma efetiva identificação com a figura da personagem e seus aspectos psicológicos, embora admitam que um afeto seja o bastante para a criação, como visto na entrevista $\mathbf{n}^{\mathbf{0}}$. 15: “(...) você que gosta de um personagem mesmo que não se identifique com ele, já é um bom motivo prá um cosplay". Aliás, é interessante notar o afeto envolvido em produzir um cosplay como o percebido nas entrevistas $\mathbf{n}^{\circ}$ 20 e $\mathbf{n}^{\circ} 22$ respectivamente: “(...) porque para fazer cosplay tem que gostar disso, da origem japonesa, então é uma coisa ligada à outra... por que se eu escutar falar mal do meu personagem eu já tomo as dores dele", e, "Sim... sentimento que não dá pra explicar é muito bom... eu fico feliz, de sair... nem que seja longe, encontrar com os amigos, poder se divertir com os cosplay, tirar fotos, é muito bom".

Isto está de acordo com o que Coelho Junior e Silva ${ }^{21}$ e Galinkin e Costa ${ }^{22}$ informam sobre a impressão visual que algumas personagens possuem e que podem cativar o adolescente consumidor dessa mídia. $\mathrm{O}$ aspecto físico da personagem é um motivo que pode determinar a escolha para se fazer o cosplay.

Foi questionado aos sujeitos se haveria alguma relação entre o contato com as produções de cultura de massa, isto é, animês e mangás, e a sua personificação enquanto cosplayers. A maioria, cerca de $65 \%$ respondeu afirmativamente. Isto pode ser exposto nos dizeres do entrevistado $\mathbf{n}^{\circ} \mathbf{1}$ :

"Exato... é por que a maioria dos cosplays é... são baseadas em personagens de animê e mangá (...) inicialmente tem aquele choque que... acontece muito das pessoas dizem 'ah, desenho japonês, desenho é coisa... de criança, bom não vou assistir'... e quando assiste acaba amando e faz o cosplay tempos depois".

Ou pelo que foi perscrutado na entrevista $\mathbf{n}^{\circ}$ 10:

"Olha... só posso falar que como gosto muito desses desenhos... revistinha em quadrinho, isso, essas coisas, eu gosto também... dos personagens. Então deve ser por isso que eu fico motivado, ou gosto disso, deve ser assim... (...)".

O discurso negativo sobre uma possível relação girou em torno de explanações como a que se teve na entrevista $\mathbf{n}^{\circ} \mathbf{2}$ :

"Bem, não. Eu, eu acho que a influência é para quem não tem cabeça (...) não se deve levar para este lado de... porque tudo isso é um... um simples fato de diversão, não deve ser levado em conta na vida real".

A Tabela 2 indica as representações dos informantes acerca dos cosplays. Tratam-se das representações que os sujeitos possuem dos cosplays conforme indicado. Neste sentido, tratase de dados não-excludentes onde um mesmo entrevistado pode ter emitido várias respostas.

Tabela 2: Representações dos Informantes acerca de Cosplays

\begin{tabular}{|c|c|}
\hline Representação & $\%$ \\
\hline Diversão & 45,5 \\
\hline Fantasia & 18 \\
\hline Mangá/Animé & 17 \\
\hline Interpretação & 12,5 \\
\hline Japão & 5 \\
\hline Sentimento de Paz & 2 \\
\hline Total & 100 \\
\hline
\end{tabular}

Como se percebe, a representação mais importante para os respondentes foi Diversão, ou seja, eles acreditam que os cosplays são uma maneira a mais de se entreter. Seria também uma forma de reunir as pessoas, ou reencontrar aquelas que estão afastadas. Talvez, inclusive seja uma nova maneira de lidar com o crescente individualismo social. Além disso, está relacionado como Barral $^{2}$ indica com a supervalorização da sociedade de entretenimento, isto é, uma forma mais moderna e sofisticada de lazer juvenil.

A segunda representação mais escolhida foi Fantasia, o que pode indicar a capacidade dos personagens de estimular a criação dos cosplays. Como foi visto na entrevista $\mathbf{n}^{\circ}$ 17: “(...) Ah porque é legal sabe?! Você pode imitar os personagens, aí é legal você pode imaginar que você é o animê." É, também, uma maneira de 
reproduzir o seu personagem favorito, mobilizando a subjetividade na tentativa de resolver as questões de identificação. Segundo Galinkin e Costa ${ }^{25}$ as representações contidas nas imagens dos desenhos favorecem na formação de condutas dos consumidores, e devido este grande impacto podese dizer que isto explica esta maneira de agir.

A seguir, Mangá/Animé são significados que tem haver com a produção artística em questão. Na medida em que as pessoas vão consumindo este tipo de mídia elas vão se identificando, como visto anteriormente, e o resultado final será o cosplay. Este componente binomial (mangá/animé) é a base do surgimento do fenômeno aqui estudado ${ }^{24}$.

A quarta categoria descrita é Interpretação que segue basicamente o exposto na 'Fantasia'. Interpretar conforme Luyten 5 é algo muito comum aos cosplayers, pois ao recriar o personagem, as pessoas tendem a seguir os comportamentos expressos por eles, inclusive a forma de andar e falar. É uma forma de interpretação cujo exemplo pode ser visto nesta fala da entrevistada $\mathbf{n}^{\circ} \mathbf{2 5}$ :

“(...) imitar um personagem que você gosta... não imitar eu não diria... interpretar um personagem que você gosta (...)."

Isto parece trazer satisfação aos cosplayers. Quanto mais parecido, mais fácil é a interpretação, e mais próximo do papel escolhido a pessoa está.

A quinta categoria de representação citada foi Japão, tendo em vista que se trata de uma produção de cultura de massa originária deste país. Os respondentes possuem noções acerca da cultura nipônica, pois aqui se formou uma grande colônia deste povo tornando familiares seus hábitos e costumes. Por exemplo, isto é expresso pela entrevistada $\mathbf{n}^{\circ} \mathbf{6}$ :

"Ah, foi legal. Porque, é diferente a revista, porque você tem que ler ao contrário, $e$ isso é isso é bom por que conserva a cultura do país, do Japão. É, há muito tempo eu já gosto do Japão, admiro a cultura e... eles não buscam a guerra igual aos americanos, eles buscam mais a harmonia."
E Finalmente Sentimento de Paz representando a busca pelo refúgio, de abrigo diante de uma realidade social complexa. Na falta de paz, esta arte pode incrementar o campo imagético destes jovens e facilitar não o encontro com a solução de todos os problemas, mas sim uma maneira de tentar lidar com os mesmos e trazer alivio. Substituindo em parte a realidade pela condição de se realizar uma fantasia, tal sentimento surge como uma espécie de 'efeito placebo' ${ }^{24}$. O exemplo exposto pode ser visto com a entrevista $\mathbf{n}^{\circ} \mathbf{4}$ :

"O motivo é muito simples. Eu gosto de assistir o desenho, é uma coisa que me faz bem sabe? (...) é uma das únicas coisas que acontecem de boa no dia-a-dia da gente. $O$ mundo é tão cruel, e esse desenho é tão assim, cheio de amor pelo próximo."

Lembrando o trabalho de Galinkin e $\operatorname{Costa}^{22}$, alguns achados significativos nesta pesquisa se relacionam à produção das histórias em quadrinhos, em geral como algo derivado da sociedade de entretenimento (foco essencial nas diversões de origem midiática que convergem para as variadas coletividades). Deixa-se aí entrever a exaltação do individual como ideologia encoberta apoiando densos recursos visuais que permitem a submissão da subjetividade alheia e fortalecimento da indústria de cultura de massa. Em sua pesquisa, estes autores identificam algumas marcas que são importantes do aparelho de mass media na vinculação da identificação do sujeito ao objeto produzido:

- Expressão narcisista do corpo;

- Atributos físicos exuberantes;

- Valorização do corpo em detrimento da reflexão e verbalização;

- Expressões histriônicas das personagens.

Isto se coaduna ao que está patente na exposição de Coelho Junior e Silva ${ }^{21}$, onde fica clara a influência demandada por estes conteúdos na identificação social que se forma por parte de adolescentes e jovens adultos que tiveram contato com estes produtos de mídia. Sendo assim, fica facilitado ao indivíduo realizar sua própria pro- 
dução que, por sua vez, para constituir a fantasia do personagem basta contar com a criatividade do cosplayer.

A roupa do cosplay deve ser produto de materiais de baixo custo, embora não seja regra geral. Quanto mais semelhante ao dito cujo personagem, mais rica e real será sua exibição. Segundo Niu e Sternberg ${ }^{19}$, a criatividade dos artistas está ligada ao formato da cultura e a motivação pessoal dos mesmos. Pode-se dizer mesmo que, quanto mais a cultura seja independente de outras, mais os artistas poderão ser criativos. Neste caso, levando-se em conta que a cultura brasileira é uma amálgama de tantas outras, poder-se-ia crer que a cultura japonesa por ser mais independente e 'fechada' teria seus cosplayers mais criativos que os do Brasil, embora tal fato não seja relevante neste estudo.

Enfim, a 'arte' que se produz a partir dos cosplays é um produto não somente da influência midiática, mas também de uma 'falta' que se apresenta no registro da realidade social. É uma falta bem consciente e dolorosa que evoca a incompatibilidade de se resolver as situações mais escabrosas de um cotidiano um tanto marcado pelas incongruências que a própria subjetividade humana promove. Tal produção artística pode ser uma maneira de se liberar das angústias do dia-a-dia promovendo a autocentração em si, levando a uma comunhão com outras pessoas e debelando um pouco a crescente individualização da sociedade humana, embora seja resultante da mesma. Lembrando Coelho ${ }^{23}$ : "Para nós, indivíduos pertencentes a uma cultura 'branca', ocidental, capitalista, sentimento e razão aparecem como funções separadas e até antagônicas. O racional, o exato, o claro, o correto não podem conviver com o infantil, o inexato, o irracional - o sentimento.” (p. 105). Ou seja, na premência de imensas responsabilidades tão naturais à sociedade moderna de maneira geral, a produção dos cosplayers serve como um anteparo advindo do imaginário que estes jovens mantém contra a dolorosa realidade.

Ao se ver do que tratam algumas formulações de autores que pesquisam nesta área ${ }^{22,24,25}$ nota-se que independente das formas de artes produzidas e de como seja produzida, ela tende a vir carregada de ideologias que acometem seus consumidores formalizando conjuntos de procedimentos sociais que como os cosplays se concretizam não nos desejos mas nos atos destas pessoas, isto é, a mídia se reproduz nos comportamentos das pessoas. Visto o que foi contemplado até o momento, faz-se mister concluir com alguns adendos inerentes á especificidade do tema.

\section{CONCLUSÃO}

Como afirmam Campos e Jobim e Souza ${ }^{1}$, os conteúdos midiáticos são mais facilmente sedimentados a partir da infância. Levando-se em conta alguns dos resultados obtidos, percebese que a subjetividade dessas pessoas pode estar talvez influenciada principalmente pela mídia televisiva, conforme visto por alguns autores $^{3,4,13}$. A Televisão parece ainda ser um dos grandes núcleos influenciadores que consegue alterar a representação que se tem acerca da realidade.

Se, de um lado na cultura japonesa existe um circuito fechado e rígido que dificulta a expressão do sujeito ${ }^{18}$, na cultura Ocidental existe um favorecimento do individualismo. Os principais resultados deste breve estudo são: os cosplays possibilitam uma identificação social com um determinado grupo; isto ocorre a partir de uma produção das culturas de massas evitando assim uma perda de referencial social, mesmo que isto tenha que ocorrer a partir de um subterfúgio visto como sendo infantilizado. Pesquisas devem ser realizadas no intento de conhecer quais seriam os efeitos refletidos tanto nas famílias como nas instituições escolares dos cosplayers, não abarcados aqui. Por fim, a identificação que resulta da constituição do cosplay passa a ser um instrumento de otimização das relações sociais, outrora empobrecido e defasado pelo individualismo crescente e, por assim dizer, um placebo temporário baseado numa nova espécie de lazer em voga na modernidade. Como refúgio do imaginário juvenil somente resta a frase de uma entrevistada $\left(\mathbf{n}^{\circ}\right.$ 4) acerca da necessidade de ser cosplayer: 
“(...) o bom é que... quando a gente gosta muito de uma pessoa a gente tenta aproveitar o máximo o que ela tem de bom prá dar a gente, e quando é cosplay aquela imagem bacana, você se sente bem se vendo como o personagem que você gosta, o desenho que você gosta. (...) Tá brincando de ser a pessoa que você gosta."

\begin{abstract}
This study aimed to understand what makes people produce cosplays, that is, what originates the behavior of dressing up as animated cartoon and anime heroes, mostly the Japanimation (Japanese animated cartoons), and the consequences of such motivation. Data collection occurred between October 2003 and October 2004 in the cities of São Paulo (state of São Paulo) and Aracaju (state of Sergipe), both in Brazil, and the sample consisted of 26 participants with an average age of 17.5 years $(S D=3.42)$. Qualitative analysis was utilized in the format of interviews to better detect the occurrence of the phenomenon and its explanation. The results demonstrated that the youngsters have such preference because they distance themselves from their daily context. That is, the fact of adopting the characters' profile and, mainly, dressing like them, impersonating them, would be a way of searching for well-being, which would help them to maintain their daily balance.
\end{abstract}

Key word: Cosplay. Japanese animated cartoons. Mangas. Otakus. Mass culture.

\section{REFERÊECIAS}

1. Campos CCG, Jobim e Souza S. Mídia, cultura do consumo e constituição da subjetividade na infância. Psicologia: Ciência e Profissão. 2003;23(1):12-21.

Barral E. Otaku: os filhos do virtual. São Paulo: Senac; 2000.

2. Mancebo D. Modernidade e produção de subjetividades: breve percurso histórico. Psicologia: Ciência e Profissão. 2002;22(1):100-11Strasburger VC. Os adolescentes e a mídia: impacto psicológico. Porto Alegre: Artmed; 1999.

3. Vazquez MAV, Clemente M. A atração pela violência midiática. Psico (Porto Alegre). 2000;31(2):49-80.

4. Akemi S. Os cosplayers [acesso em 31 ago 2003]. Disponível em: www.cosplaybr.kit.net.com.br.

5. Luyten SB. O tripé japonês. Bravo; 2004;86(8):51-3.

6. Doise W. Da psicologia social a psicologia societal. Psicologia: Teoria e Pesquisa. 2002;18(1):27-35. Farr R. As raízes da psicologia social moderna. Petrópolis: Vozes; 1996.

7. Moscovici S. Representações sociais: investigações em psicologia social. Petrópolis: Vozes; 2003.

8. Coelho Junior LL. Um estudo sobre a violência em duas histórias gráficas. Rev Bras Crescimento Desenvolv Hum. 2005;15(2):55-68.
9. Luyten SB. Mangá: o poder dos quadrinhos japoneses. São Paulo: Hedra; 2002.

10. Moliné A. O grande livro dos mangás. São Paulo: JBC; 2004.

11. Meireles SM. O ocidente redescobre o Japão: o boom de mangás e animes. Revista de Estudos Orientais. 2003;4(1):203-11.

12. Parente J. O efeito mangá. Bravo. 2004;86(8):46-50.

13. Andrade PR. Correlatos valorativos da preferência por desenhos animados: compreendendo a justificação da agressão [dissertação]. João Pessoa: Universidade Federal da Paraíba; 2003.

14. Bosi E. Cultura de massa e cultura popular. Petrópolis: Vozes; 2000.

15. Benedict R. O crisântemo e a espada. São Paulo: Perspectiva; 2002.

16. Siebra LMG. Considerações teóricas acerca da utilização da pesquisa qualitativa. Revista de Psicologia. 1999/2000;18(1-2):30-9. título do periódico deve ser abreviado de acordo com o Index Medicus

17. González Rey FL. Pesquisa qualitativa em psicologia: caminhos e desafios. São Paulo: Thomson Pioneira; 2002.

18. Araújo DRD. Como transcrever sua entrevista: técnica de editoração da transcrição de entrevista em pesquisa de abordagem compreensivista. Psico (Porto Alegre). 2001;31(1):147-57. 
19. Niu W, Sternberg RJ. Cultural influences on artistic creativity and its evaluation. International journal of psychology. 2001;36(4):225-41. título do periódico deve ser abreviado de acordo com o Index Medicus

20. Conselho Federal de Psicologia. XIV Resolução MS n 196/96. Em: Psicologia: Legislação (org.), n 8 (pp. 235-259). DF: CFP. 1999.

21. Coelho Junior LL, Silva SS. Cosplayers como fenômeno psicossocial [CD-ROM]. In: Anais da 34. Reunião da Sociedade Brasileira de Psicologia; 2004, out 26-29; Ribeirão Preto, Brasil. Ribeirão Preto: USP; 2004.

22. Galinkin AL, Costa FBA. Representações sociais de gênero e violência nas histórias em quadrinhos [CD-ROM]. In: Anais da 34. Reunião da Sociedade Brasileira de Psicologia; 2004, out 26-29; Ribeirão Preto, Brasil. Ribeirão Preto: USP; 2004.

23. Coelho MHM. O ator e as emoções. Psicologia Revista. 2000;(10):105-15.

Recebido em 03/08/2006

Modificado em 07/10/2006

Aprovado em 07/11/2006 


\section{ANEXO}

\section{QUESTIONÁRIO DE IDENTIDADE SOCIAL DE COSPLAYERS}

1- Idade:

2- Sexo:

3- Nome do Cosplay:

4- Qual a história deste personagem?

5- Porque você escolheu este personagem?

6- Há quanto tempo você faz cosplay?

7- Foi difícil você fazer este cosplay?

8- Você vê animes ou lê mangás? Há quanto tempo?

9- Crê que haja influência entre animês e mangás e você estar fazendo cosplays?

10- Existe alguma espécie de afeto entre o cosplayer e o personagem escolhido?

11- Diga duas (2) palavras que lhe vêm a cabeça quando você escuta a palavra "Cosplay". 